\title{
Investigation of the direct runoff generation mechanism for the analysis of the SCS-CN method applicability to a partial area experimental watershed
}

\author{
K. X. Soulis, J. D. Valiantzas, N. Dercas, and P. A. Londra \\ Agricultural University of Athens, Department of Natural Resources Management and Agricultural Engineering, Lab. of \\ Agricultural Hydraulics, Athens, Greece
}

Received: 19 November 2008 - Published in Hydrol. Earth Syst. Sci. Discuss.: 16 January 2009

Revised: 24 March 2009 - Accepted: 8 May 2009 - Published: 15 May 2009

\begin{abstract}
The Soil Conservation Service Curve Number (SCS-CN) method is widely used for predicting direct runoff volume for a given rainfall event. The applicability of the SCS-CN method and the direct runoff generation mechanism were thoroughly analysed in a Mediterranean experimental watershed in Greece. The region is characterized by a Mediterranean semi-arid climate. A detailed land cover and soil survey using remote sensing and GIS techniques, showed that the watershed is dominated by coarse soils with high hydraulic conductivities, whereas a smaller part is covered with medium textured soils and impervious surfaces. The analysis indicated that the SCS-CN method fails to predict runoff for the storm events studied, and that there is a strong correlation between the $\mathrm{CN}$ values obtained from measured runoff and the rainfall depth. The hypothesis that this correlation could be attributed to the existence of an impermeable part in a very permeable watershed was examined in depth, by developing a numerical simulation water flow model for predicting surface runoff generated from each of the three soil types of the watershed. Numerical runs were performed using the HYDRUS-1D code. The results support the validity of this hypothesis for most of the events examined where the linear runoff formula provides better results than the SCS-CN method. The runoff coefficient of this formula can be taken equal to the percentage of the impervious area. However, the linear formula should be applied with caution in case of extreme events with very high rainfall intensities. In this case,
\end{abstract}

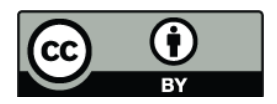

Correspondence to: K. X. Soulis (soco@aua.gr) the medium textured soils may significantly contribute to the total runoff and the linear formula may significantly underestimate the runoff produced.

\section{Introduction}

The Soil Conservation Service Curve Number (SCS-CN) method is widely used for predicting direct runoff volume for a given rainfall event. This method was originally developed by the US Department of Agriculture, Soil Conservation Service and documented in detail in the National Engineering Handbook, Sect. 4: Hydrology (NEH-4) (SCS 1956, 1964, 1971, 1985, 1993). Due to its simplicity, it soon became one of the most popular techniques among the engineers and the practitioners, mainly for small catchment hydrology (Mishra and Singh, 2006).

The main reasons for its success is that it accounts for many of the factors affecting runoff generation including soil type, land use and treatment, surface condition, and antecedent moisture condition, incorporating them in a single $\mathrm{CN}$ parameter. Furthermore, it is the only methodology that features readily grasped and reasonably well-documented environmental inputs and it is a well established method, widely accepted for use in the United States and other countries. On the other hand, the SCS-CN main weak points are the following: it does not consider the impact of rainfall intensity and its temporal distribution, it does not address the effects of spatial scale, it is highly sensitive to changes in values of its sole parameter; and it does not address clearly the

Published by Copernicus Publications on behalf of the European Geosciences Union. 
effect of adjacent moisture condition (Hawkins, 1993; Ponce and Hawkins, 1996; Michel et al., 2005).

Although the SCS method was originally developed in the United States and mainly for the evaluation of storm runoff in small agricultural watersheds, it soon evolved well beyond its original objective and was adopted for various land uses such as urbanized and forested watersheds (Rawls et al., 1981; Mishra and Singh, 1999). Its scope also expanded beyond the evaluation of storm runoff and it became an integral part of more complex, long-term, simulation models (e.g. Choi et al., 2002; Holman et al., 2003; Lyon et al., 2004; Mishra and Singh, 2004; Zhan et al., 2004; Mishra et al., 2005a; Soulis and Dercas, 2007; Geetha et al., 2008; Moretti and Montanari, 2008; Singh et al., 2008; Tyagi et al., 2008; etc).

Due to the widespread use and the general acceptance of the method, its applicability was investigated in various regions and for various land uses and climate conditions, while $\mathrm{CN}$ values were obtained experimentally from rainfall and runoff measurements over a wide range of geographic, soil, and land management conditions (Romero et al., 2007; King and Balogh, 2008). The SCS-CN method has been also the subject of many studies aimed at finding a theoretical basis for the method, facilitating the use of the method in regions and for climate conditions not previously evaluated, and supporting its further improvement (Hjelmfelt, 1991; Yu, 1998).

In spite of the widespread use of this method, there is not an agreed procedure to estimate $\mathrm{CN}$ from measured runoff. Many methods were proposed leading to different $\mathrm{CN}$ values. The main difficulty is the large variability observed in the $\mathrm{CN}$ values evaluated for the same watershed for various rainfall depths. This variability was attributed to variations in the antecedent moisture conditions, to the temporal and spatial variability of rainfall, to scale effects, and many other reasons. Therefore, many studies aimed at improving the method and finding a better way to incorporate the Antecedent Moisture Conditions (AMC) (e.g. Simanton et al., 1996; Mishra et al., 2005b; Jain et al., 2006; Sahu et al., 2007; Brocca et al., 2008; Kannan et al., 2008; Mishra et al., 2008).

Hawkins $(1973,1979)$ for a certain number of watersheds in the US indicated the presence of a correlation between the $\mathrm{CN}$ values and the rainfall depth. He attributed this correlation to the existence of an impermeable area in the basin, which mainly contributes to the total runoff. For this type of watersheds, he stated that the use of a runoff coefficient can be more accurate than the use of the SCS-CN method. His hypothesis was criticized on the ground that it was mainly based on indications only and, therefore, the mechanism still lacked detailed investigation (Roger, 1980). Hawkins (1993), in a later study proposing a method to evaluate $\mathrm{CN}$ values from measured runoff, distinguished watersheds in three categories depending on the type of correlation between rainfall and $\mathrm{CN}$ values calculated from measured runoff, namely watersheds with standard behaviour, violent behaviour, and complacent behaviour. In the latter category, the estimation of a single $\mathrm{CN}$ value was not possible, since $\mathrm{CN}$ value was decreased steadily as rainfall depth was increased. He described them as mainly forested watersheds with very permeable soils. The assumption of the existence of such watersheds presenting the above mentioned behaviour could be also supported by the Dingman's (2002) statement that many of the natural soils have saturated hydraulic conductivity values, $K_{s}$, much higher than the normal range of rainfall intensities. Furthermore, the analysis of the Soil Geographical Database of Eurasia (2004) indicates that the coarse soils, presenting very high $K_{S}$ values, cover about $37 \%$ of the surveyed area.

In the previous studies, the criteria developed for the applicability of SCS-CN method require essentially the knowledge of runoff data. However, the SCS-CN method is mainly developed to be applied in ungauged watersheds. Consequently,,it is necessary to analyse systematically the key characteristics of the watershed that are responsible for this behaviour in order to provide some indicators that could facilitate the evaluation of the applicability of the SCS-CN method in ungauged watersheds..

Thus, the main objective of this study is to investigate the fundamental mechanism for the generation of surface runoff, as well as to analyse the SCS-CN method applicability in a Mediterranean experimental watershed presenting similar behaviour. A detailed soil and land cover survey, along with the existence of a dense rain gauge network and detailed runoff measurements, facilitated the in depth evaluation of the SCS-CN method applicability in the study area. Furthermore, a runoff generation numerical simulation model was developed for the case study area, in order to thoroughly analyze the fundamental mechanism of runoff generation and to justify the existence of such behaviour.

\section{SCS-CN method}

The SCS-CN method is based on the water balance equation

$P=I_{a}+F+Q$

and on the fundamental assumption that the ratio of runoff to effective rainfall is the same as the ratio of actual retention to potential retention,

$$
\frac{Q}{P-I_{a}}=\frac{F}{S}
$$

where $P$ is the total rainfall, $I_{a}$ is the initial abstraction, $F$ is the cumulative infiltration excluding $I_{a}, Q$ is the direct runoff and $S$ is the potential maximum retention. The combination of Eqs. (1) and (2) yields the basic form of the SCS$\mathrm{CN}$ method

$Q=\frac{\left(P-I_{a}\right)^{2}}{P-I_{a}+S}$,

which is valid for $P \geq I_{a}$; otherwise $Q=0$. 


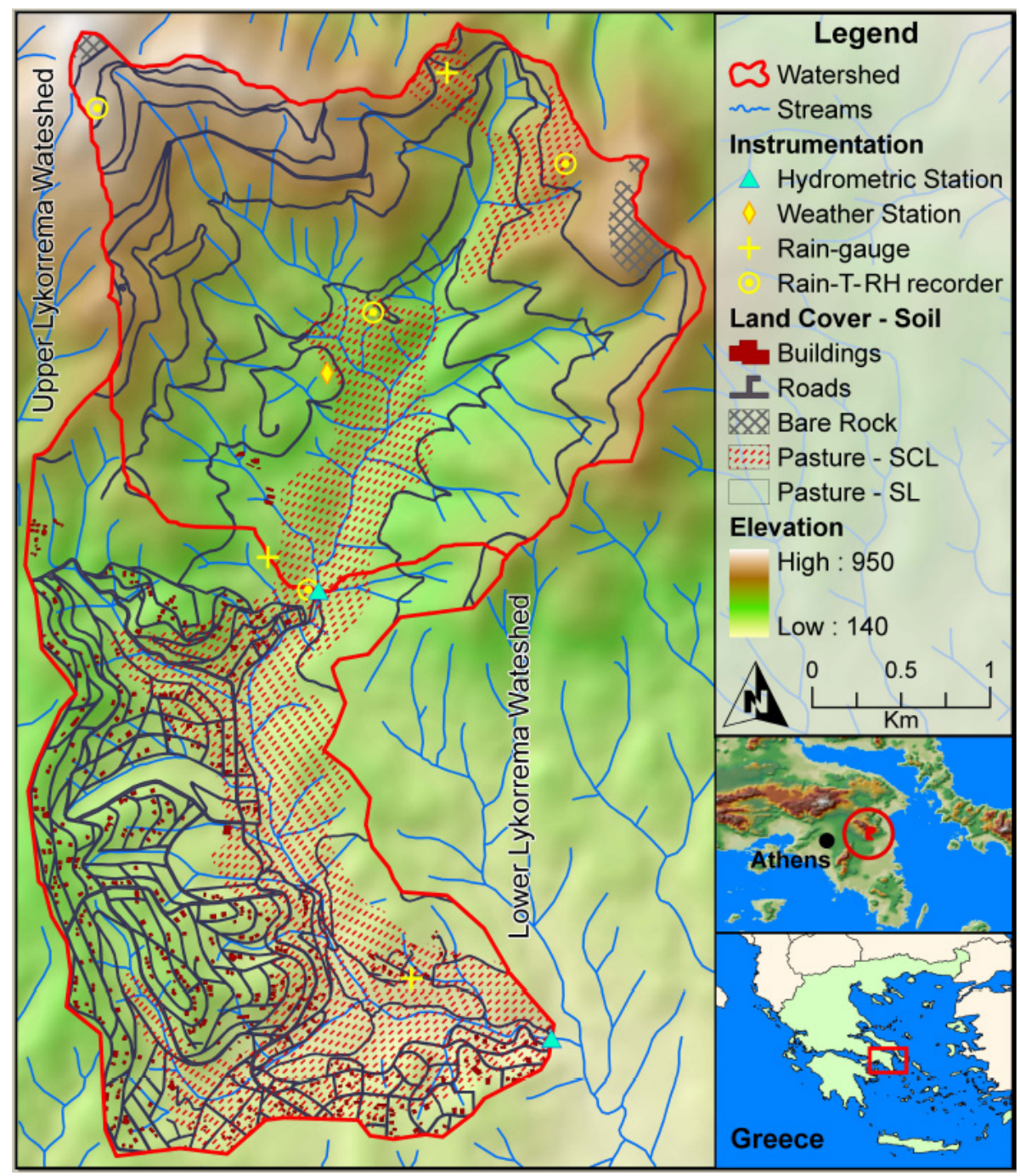

Fig. 1. Map of the Lykorrema experimental watershed.

Based on a second assumption, that the amount of initial abstraction is a fraction of the potential maximum retention

$I_{a}=\lambda S$,

Eq. (3) becomes

$Q=\frac{(P-\lambda S)^{2}}{P+(1-\lambda) S}$.

In Eq. (5), the initial abstraction rate is normally set to a constant value $(\lambda=0.2)$ in order for $S$ to be the only parameter of the method. Furthermore, the potential retention $S$ is expressed in terms of the dimensionless curve number $(\mathrm{CN})$ through the relationship

$S=\frac{25400}{\mathrm{CN}}-254$
$\mathrm{CN}$ values can be obtained from tables for various soil types, land cover and land management conditions, however $\mathrm{CN}$ estimation based on real data from local or nearby similar watersheds is preferable.

In order to estimate $S$ from real data, Eq. (5) can be solved by the quadratic formula to (Hawkings, 1979)

$S=5\left(P+2 Q-\sqrt{4 Q^{2}+5 P Q}\right)$.

Combining Eq. (7) with Eq. (6), CN value can be directly estimated from rainfall and runoff data

$$
\mathrm{CN}=\frac{25400}{5\left(P+2 Q-\sqrt{4 Q^{2}+5 P Q}\right)+254} .
$$

with $S$, in mm, taking values from 0 , when $S \rightarrow \infty$, to 100 , when $S=0$. 


\section{Study area}

The study area includes the small scale experimental watershed of Lykorrema stream $\left(15.2 \mathrm{~km}^{2}\right)$, situated in the east side of Penteli Mountain, Attica, Greece (Coordinates: UL $23^{\circ} 53^{\prime} 23^{\prime \prime} \mathrm{E}-38^{\circ} 04^{\prime} 13^{\prime \prime} \mathrm{N}$; LR $\left.23^{\circ} 56^{\prime} 00^{\prime \prime} \mathrm{E}-38^{\circ} 00^{\prime} 47^{\prime \prime} \mathrm{N}\right)$ (Fig. 1). The region is characterized by a Mediterranean semi-arid climate with mild, wet winters and hot, dry summers. Precipitation occurs mostly in the autumn-spring period. The yearly average precipitation value for the five years studied is $595 \mathrm{~mm}$. The reference evapotranspiration rate varies from about $1 \mathrm{~mm}$ /day during winter to $7 \mathrm{~mm} /$ day during summer. The hydrographic network of the watershed is particularly dense including fifth-order streams according to the Strahler (1952) method.

The watershed is divided in two sub-watersheds. The Upper Lykorrema watershed $\left(7.84 \mathrm{~km}^{2}\right)$ presents a relatively sharp relief, with elevations ranging between $280 \mathrm{~m}$ and $950 \mathrm{~m}$. Its average elevation is $560 \mathrm{~m}$ and its average slope is as high as $36 \%$. Geologically it is characterized by schists formations covering $96 \%$ of its area, while the rest is covered by marbles. Schist formations in the area are not impervious. They are tectonically intensely fractured and their upper layer is eroded (Baltas et al., 2007). The Lower Lykorrema watershed $\left(7.36 \mathrm{~km}^{2}\right)$ also presents a relatively sharp relief with elevations ranging between $146 \mathrm{~m}$ and $643 \mathrm{~m}$. Its average elevation is $310 \mathrm{~m}$ and its average slope is $21 \%$. Geologically it is characterised by tertiary deposits covering $70 \%$ of its area, while schists and marbles covering $26 \%$ and $4 \%$ respectively.

A soil survey in the area, showed that the watershed is dominated by coarse soils with high hydraulic conductivities and a smaller part is covered with medium textured soils presenting relatively high hydraulic conductivities (Table 1). A detailed land cover classification based on remote sensing techniques, showed that the dominant vegetation type in the watershed is pasture with a few scattered tufts of trees. There is also a dense road network, mainly in the lower part of the watershed, where a settlement exists. A small part of the watershed is covered by bare rock (Fig. 1). In this study, the stream-channel surface, the roads, the buildings and the bare rock were supposed to be impervious areas. The detailed extent of the impervious surfaces was precisely measured with Geographical Information Systems techniques using aerial and satellite imagery (Table 1). It was found that impervious surfaces cover $5.06 \%$ and $10.07 \%$ of the Upper and Lower Lykorrema watershed respectively, which corresponds to $7.48 \%$ of the total watershed area.

The aquifers system developed within the intensely fractured bedrock contributes significantly to the base flow of the watershed, which is continuous throughout the year. Generally, there is not an immediate response of base flow rate to the storm events. During wet years the base flow rate increases continuously till late Spring whereas in dry years base flow rate decreases slowly throughout the year. The
Table 1. Summary of watersheds characteristics.

\begin{tabular}{lllc}
\hline Watershed & Soil Type * & Land Cover & Area $\left(\mathrm{km}^{2}\right)$ \\
\hline Upper Lykorrema & SL & Pasture & 6.049 \\
& SCL & Pasture & 1.393 \\
& - & Stream-Channels & 0.002 \\
& & Roads & 0.267 \\
Lower Lykorrema & & Buildings & 0.004 \\
& SL & Rock & 0.128 \\
& SCL & Pasture & 3.658 \\
& - & Pasture & 2.962 \\
& & Stream-Channels & 0.004 \\
& & Roads & 0.570 \\
& & Buildings & 0.167 \\
\hline
\end{tabular}

*SL: Sandy Loam; SCL: Sandy Clay Loam

Base Flow Index (BFI - the long-term proportion of base flow on total stream flow) for the Upper Lykorrema watershed is 0.79 and for the entire watershed is 0.75. Schneider et al. (2007) correlated the BFI values with hydrological soil characteristics and Longobardi and Villani (2008) correlated high BFI values to high watershed permeability. Consequently, the high observed BFI values are in agreement with the above referred studies, since the studied watershed is dominated by coarse soils with high hydraulic conductivities.

Finally, the $\mathrm{CN}$ values were estimated for both watersheds according to the tables and the methodology provided in $\mathrm{NEH}-4$. The weighted $\mathrm{CN}$ values were equal to 51 and 55 for the Upper Lykorrema watershed and for the entire watershed, respectively.

\section{Storm events}

The study area is equipped with a dense hydrometeorological network, which is fully operational since September 2004. The installed equipment consists of seven rain-gauges, two hydrometric stations at the outlet of each sub-watershed, one meteorological station and four temperature-relative humidity recorders (Fig. 1). The data are recorded with a time step of $10 \mathrm{~min}$. The Upper and Lower Lykorrema experimental watersheds are operated from the Agricultural University of Athens and the National Technical University of Athens, respectively. In addition to the very dense rain gauge network, special care was also given to the quality of the discharge measurements. The hydrometric station of the upper sub-watershed consists of a weir and a digital water level recorder, securing the accuracy of the discharge measurements. The second hydrometric station consists of a digital water level recorder installed at a natural cross-section of the stream, while very 
Table 2. Characteristics of the storm events.

\begin{tabular}{|c|c|c|c|c|c|c|c|c|c|c|c|}
\hline \multirow[b]{2}{*}{ no. } & \multirow[b]{2}{*}{ Storm Event } & \multirow[b]{2}{*}{ Duration (h) } & \multirow[b]{2}{*}{ AMC } & \multicolumn{4}{|c|}{ Upper Lykorrema watershed } & \multicolumn{4}{|c|}{ Entire watershed } \\
\hline & & & & Rainfall (mm) & Runoff (mm) & $\mathrm{S}(\mathrm{mm})$ & $\mathrm{CN}$ & Rainfall (mm) & Runoff (mm) & $\mathrm{S}(\mathrm{mm})$ & $\mathrm{CN}$ \\
\hline 1 & $18 / 12 / 2004$ & 25 & I & 91.3 & 7.0 & 236 & 52 & 83.8 & 9.0 & 189 & 57 \\
\hline 2 & $21 / 12 / 2004$ & 10 & III & 21.2 & 1.0 & 64 & 80 & 22.1 & 1.2 & 64 & 80 \\
\hline 3 & $29 / 12 / 2004$ & 12 & I & 29.7 & 1.0 & 97 & 72 & 29.3 & 1.7 & 83 & 75 \\
\hline 4 & $31 / 12 / 2004$ & 16 & III & 28.9 & 1.4 & 86 & 75 & 25.8 & 1.8 & 68 & 79 \\
\hline 5 & $15 / 01 / 2005$ & 31 & I & 103.9 & 5.5 & 301 & 46 & 119.9 & 10.9 & 290 & 47 \\
\hline 6 & $20 / 01 / 2005$ & 18 & III & 37.3 & 2.5 & 100 & 72 & 36.1 & 3.7 & 83 & 75 \\
\hline 7 & $22 / 01 / 2005$ & 5 & III & 8.9 & 0.2 & 31 & 89 & 7.3 & 0.5 & 19 & 93 \\
\hline 8 & $31 / 01 / 2005$ & 18 & I & 35.2 & 1.1 & 118 & 68 & 33.9 & 2.3 & 92 & 74 \\
\hline 9 & $02 / 02 / 2005$ & 10 & III & 22.5 & 2.1 & 54 & 82 & 34.8 & 2.6 & 91 & 74 \\
\hline 10 & $15 / 02 / 2005$ & 6 & I & 16.0 & 1.0 & 45 & 85 & 15.2 & 1.2 & 38 & 87 \\
\hline 11 & $23 / 02 / 2005$ & 9 & I & 18.2 & 0.6 & 60 & 81 & 17.1 & 1.1 & 47 & 84 \\
\hline 12 & $25 / 02 / 2005$ & 4 & II & 11.5 & 0.3 & 40 & 87 & 9.6 & 0.7 & 26 & 91 \\
\hline 13 & $01 / 03 / 2005$ & 16 & I & 13.4 & 0.5 & 43 & 85 & 11.4 & 0.8 & 30 & 89 \\
\hline 14 & $04 / 03 / 2005$ & 12 & I & 18.0 & 0.7 & 57 & 82 & 11.2 & 1.0 & 28 & 90 \\
\hline 15 & 06/08/2005 & 2 & I & 21.0 & 1.6 & 54 & 82 & 5.5 & 0.3 & 16 & 94 \\
\hline 16 & $23 / 09 / 2005$ & 7 & I & 35.2 & 1.9 & 102 & 71 & 35.8 & 2.3 & 98 & 72 \\
\hline 17 & $17 / 11 / 2005$ & 21 & I & 59.4 & 3.0 & 175 & 59 & 46.1 & 1.8 & 145 & 64 \\
\hline 18 & $22 / 11 / 2005$ & 22 & III & 114.1 & 6.1 & 330 & 43 & 77.3 & 6.9 & 189 & 57 \\
\hline 19 & $24 / 11 / 2005$ & 21 & III & 85.0 & 5.1 & 237 & 52 & 82.3 & 7.8 & 196 & 56 \\
\hline 20 & $25 / 11 / 2005$ & 9 & III & 31.6 & 2.4 & 82 & 76 & 47.5 & 6.1 & 99 & 72 \\
\hline 21 & $26 / 11 / 2005$ & 11 & III & 15.3 & 0.6 & 48 & 84 & 15.2 & 0.6 & 47 & 84 \\
\hline 22 & $05 / 02 / 2006$ & 11 & I & 59.8 & 5.1 & 148 & 63 & 53.2 & 7.1 & 108 & 70 \\
\hline 23 & 09/10/2006 & 14 & I & 38.6 & 2.2 & 109 & 70 & 46.5 & 4.1 & 114 & 69 \\
\hline 24 & $10 / 10 / 2006$ & 7 & III & 43.2 & 2.1 & 128 & 66 & 26.4 & 2.2 & 66 & 79 \\
\hline 25 & $30 / 10 / 2006$ & 38 & I & 105.9 & 6.1 & 299 & 46 & 122.9 & 14.6 & 265 & 49 \\
\hline 26 & $11 / 02 / 2007$ & 12 & I & 33.6 & 1.7 & 98 & 72 & 29.9 & 1.3 & 91 & 74 \\
\hline 27 & $22 / 03 / 2007$ & 17 & I & 72.2 & 3.4 & 217 & 54 & 68.2 & 4.8 & 182 & 58 \\
\hline 28 & $08 / 12 / 2007$ & 14 & I & 40.1 & 1.6 & 125 & 67 & 42.5 & 3.4 & 108 & 70 \\
\hline 29 & $28 / 03 / 2008$ & 23 & I & 24.0 & 1.0 & 75 & 77 & 24.2 & 2.5 & 55 & 82 \\
\hline 30 & 05/04/2008 & 16 & I & 26.3 & 1.5 & 75 & 77 & & * no available da & & \\
\hline
\end{tabular}

frequent stage-discharge measurements secure the accuracy of discharge measurements as well.

For the current analysis, all the storm events producing significant direct runoff that took place from September 2004 to August 2008 were used (30 events). A storm event was considered significant when the value of peak flow rate in the hydrograph was greater than $0.15 \mathrm{~m}^{3} / \mathrm{s}$ for the Upper Lykorrema watershed and $0.25 \mathrm{~m}^{3} / \mathrm{s}$ for the entire watershed. The end of an event was defined when a six-hour period without rainfall occurred. In Table 2 details on the characteristics of these events for the Upper Lykorrema watershed and for the entire watershed can be seen. The watershed areal rainfall estimation was made using Thiessen polygons method, while base-flow was separated using the constant slope graphical method (Dingman, 2002). The potential maximum retention $S$ and the $\mathrm{CN}$ value were directly estimated from the measured rainfall and runoff data using Eqs. (7) and (8). Antecedent Moisture Condition category (AMC) was estimated based on the previous 5-days precipitation according to the NEH-4 procedure. It must be noted, that most events belong either to the AMC I (dry) category or to the AMC III (wet) category. This probably happens because the number of wet days in Greece is normally low and storm events are separated with long periods of dry weather. A careful study of Table 2 indicates that normally in each series of wet days, the first storm event belongs to AMC I category and the following storm events in AMC III.

\section{Runoff generation numerical simulation model}

A numerical simulation model to predict surface runoff volume was applied in an effort to investigate the mechanism of runoff generation in the case study area. Based on the detailed soil survey and land cover classification carried out in the area, the watershed was categorized in three main soil land cover complexes, namely Sandy Loam (SL) - Pasture, Sandy Clay Loam (SCL) - Pasture, and impermeable surfaces.

It is assumed that the watershed is characterized by a Hortonian surface runoff generator mechanism that results from the saturation of the top soil "from above". This assumption is justified because the region, in which the watershed under study is located (Attica, Greece), is characterized by semiarid climate conditions and as Dingman (2002) reported, "the 
Hortonian surface runoff is an important response mechanism in semi-arid to arid regions".

The total amount of water, which infiltrates in each soil type of the watershed (previously described) and which is lost by surface runoff from each of the three soil types was simulated by means of the HYDRUS-1D code (Simunek et al., 1998).

In numerical runs, the observed 10-min rainfall records of the storm events, presented in Table 2, are used as inputs in order to predict the corresponding amount of surface runoff produced from each storm event and each soil type of the watershed. In HYDRUS-1D code, one-dimensional water flow in a homogeneous, rigid, variably saturated porous medium is described using Richards' equation

$$
\frac{\partial \theta}{\partial t}=\frac{\partial K(\psi)}{\partial z}\left[\left(\frac{\partial \psi}{\partial z}\right)-1\right]
$$

where $\theta$ is the volumetric water content $\left(\mathrm{L}^{3} \mathrm{~L}^{-3}\right), t$ is the time (T), $z$ is the vertical co-ordinate (positive downwards) $(\mathrm{L}), \psi$ is the pressure head $(\mathrm{L})$, and $K$ is the hydraulic conductivity $\left(\mathrm{L} \mathrm{T} \mathrm{T}^{-1}\right)$. The HYDRUS-1D code is generally considered robust, accurate and numerically reliable.

A simplified uniform soil profile was simulated for the first two soil - land cover complexes, whereas in the third case it was assumed that runoff was equal to rainfall. The depth of the soil profile was assumed to be equal to $1 \mathrm{~m}$. Test simulations with shallower or deeper soil profiles, indicated that reasonable variations in soil depth do not influence significantly the results.

To solve Eq. (9), the upper and lower boundary conditions and the initial conditions need to be specified. In this study, the upper boundary condition is defined as an atmospheric condition where potential water fluxes across the soil surface correspond to the 10-min recorded precipitation storm events (Table 2). It is assumed that no ponding occurs at the soil surface and that all excess water is removed instantaneously by surface runoff. Evapotranspiration is not considered in the simulation runs. At the lower boundary of the $1 \mathrm{~m}$ uniform soil profile, a zero pressure head gradient is defined, i.e. free-draining soil profile. The free drainage boundary conditions were chosen for the bottom of the soil profile because permeable geological formations are presented in most of the area and the aquifer was found in deep depths. An initially dry soil profile was supposed for all the events analyzed, while the simulation for the events belonging to the AMC II or AMC III category started five days earlier to take into account the antecedent precipitation as it is defined in the (SCS-CN) method.

The soil profile was discretized into 500 soil compartments to enhance the numerical stability and the accuracy of the solution. The initial conditions were given in terms of pressure heads and were all set at $1 \mathrm{~m}$.

In addition to the initial and boundary conditions, the water retention characteristics, $\theta(\psi)$, and the hydraulic conductivity curve, $K(\theta)$ or $K(\psi)$, must be specified to solve
Table 3. Soils hydraulic properties.

\begin{tabular}{llllll}
\hline $\begin{array}{l}\text { Soil } \\
\text { Type }\end{array}$ & $\begin{array}{l}\alpha \\
(1 / \mathrm{m})\end{array}$ & $\begin{array}{l}n \\
(-)\end{array}$ & $\begin{array}{l}\theta_{s} \\
\left(\mathrm{~m}^{3} \mathrm{~m}^{-3}\right)\end{array}$ & $\begin{array}{l}\theta_{r} \\
\left(\mathrm{~m}^{3} \mathrm{~m}^{-3}\right)\end{array}$ & $\begin{array}{l}K_{S} \\
\left(\mathrm{~cm} \mathrm{~h}^{-1}\right)\end{array}$ \\
\hline SL & 2.7 & 1.45 & 0.39 & 0.039 & 24 \\
SCL & 2.1 & 1.33 & 0.38 & 0.063 & 1.6 \\
\hline
\end{tabular}

Eq. (9). In this study the empirical closed-form analytical model of van Genuchten (1980) is used to describe, respectively, the water retention characteristic $\theta(\psi)$ and the $K(\theta)$ relationship. The parameters of the van Genuchten (1980) model, $\alpha, n, \theta_{s}$ and $\theta_{r}$ for each soil type, were evaluated using the Rosetta Lite Version 1.1 (Schaap et al., 2001). The saturated hydraulic conductivity value $K_{s}$, for each soil type, was evaluated by measurements taken during the soil survey. Table 3 presents the values of the above mentioned parameters for the two soil profiles.

A routing of the surface runoff produced from each of the three soil type watershed areas is not applied, since the hydrographic network is dense and all the three areas are directly connected with the hydrographic network, as can be seen in Fig. 1.

Simulation results for the Upper Lykorrema and the entire watershed are presented in Table 4 including the total surface runoff, $Q_{\mathrm{Tot}}$, the runoff portion from SL soil, $Q_{\mathrm{SL}}$, impervious surface, $Q_{\mathrm{Imp}}$, and SCL soil, $Q_{\mathrm{SCL}}$, for both watersheds and for each storm-event. Figure 2 presents a comparison of the numerically simulated surface runoff amounts with the measured runoff values for each storm event. Generally, there is a good agreement between the measured and the simulated runoff values for both watersheds. For the Upper Lykorrema watershed the numerical model performs very well, yielding a coefficient of determination $R^{2}=0.95$. The performance of the model is slightly inferior for the entire watershed $\left(R^{2}=0.88\right)$. This result may eventually be attributed to the higher rainfall variability due to the larger size of the entire watershed. The simulated runoff generated by the two different soil types is negligible for most of the events analyzed, except for two events for the SCL soil. The saturated hydraulic conductivity $K_{S}$ of the SL soil was much higher than the rainfall intensity in all cases examined, resulting in zero direct runoff for the simulated events for both watersheds. For the SCL soil, rainfall intensity was significantly higher than the $K_{S}$ in only two events (no. 1 and no. 22 in Table 4) resulting to the generation of surface runoff from this part of the watershed (maximum 10-min rainfall intensities were equal to $9.4 \mathrm{~cm} \mathrm{~h}^{-1}$ and $4 \mathrm{~cm} \mathrm{~h}^{-1}$ ). These results support the hypothesis that the watershed under study is a "partial area" watershed and that the main source of direct runoff is the impervious surfaces. However, it is evident that in some extreme events with very high rainfall intensities, some "inactive" parts of the watershed may generate 

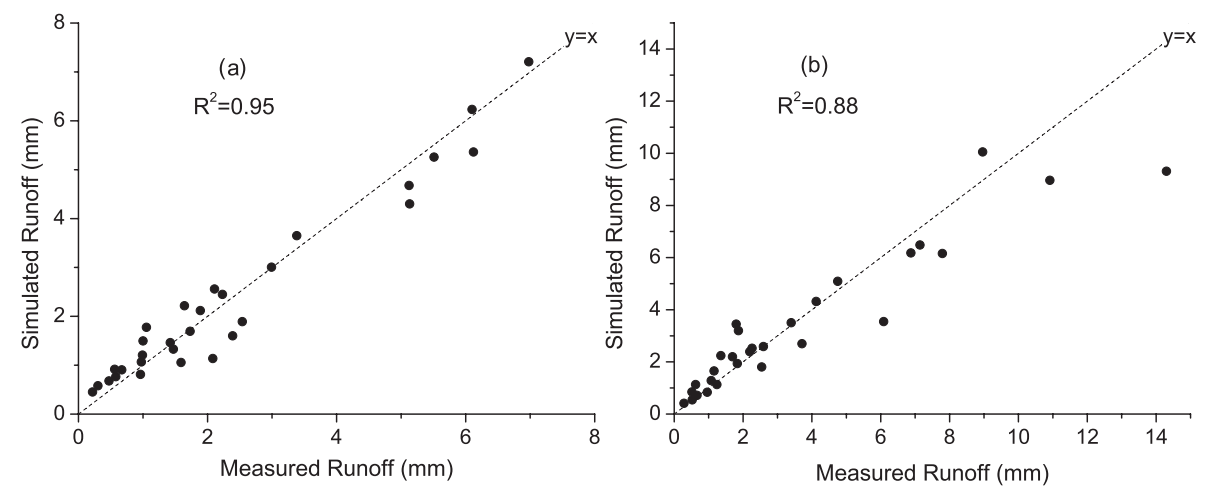

Fig. 2. Comparison of the measured and simulated surface runoff for each storm event. (a) Upper Lykorrema watershed, (b) Entire watershed.

Table 4. Numerical simulation model results.

\begin{tabular}{|c|c|c|c|c|c|c|c|c|}
\hline \multirow[b]{2}{*}{ no. } & \multicolumn{4}{|c|}{ Upper Lykorrema watershed } & \multicolumn{4}{|c|}{ Entire watershed } \\
\hline & $\mathrm{Q}_{\mathrm{SL}}(\mathrm{mm})$ & $\mathrm{Q}_{\mathrm{SCL}}(\mathrm{mm})$ & $\mathrm{Q}_{\operatorname{Imp}}(\mathrm{mm})$ & $\mathrm{Q}_{\mathrm{Tot}}(\mathrm{mm})$ & $\mathrm{Q}_{\mathrm{SL}}(\mathrm{mm})$ & $\mathrm{Q}_{\mathrm{SCL}}(\mathrm{mm})$ & $\mathrm{Q}_{\operatorname{Imp}}(\mathrm{mm})$ & $\mathrm{Q}_{\mathrm{Tot}}(\mathrm{mm})$ \\
\hline 1 & 0.00 & 2.59 & 4.62 & 7.21 & 0.00 & 3.78 & 6.27 & 10.05 \\
\hline 2 & 0.00 & 0.00 & 1.07 & 1.07 & 0.00 & 0.00 & 1.65 & 1.65 \\
\hline 3 & 0.00 & 0.00 & 1.50 & 1.50 & 0.00 & 0.00 & 2.20 & 2.20 \\
\hline 4 & 0.00 & 0.00 & 1.46 & 1.46 & 0.00 & 0.00 & 1.93 & 1.93 \\
\hline 5 & 0.00 & 0.00 & 5.26 & 5.26 & 0.00 & 0.00 & 8.97 & 8.97 \\
\hline 6 & 0.00 & 0.00 & 1.89 & 1.89 & 0.00 & 0.00 & 2.70 & 2.70 \\
\hline 7 & 0.00 & 0.00 & 0.45 & 0.45 & 0.00 & 0.00 & 0.55 & 0.55 \\
\hline 8 & 0.00 & 0.00 & 1.78 & 1.78 & 0.00 & 0.00 & 2.53 & 2.53 \\
\hline 9 & 0.00 & 0.00 & 1.14 & 1.14 & 0.00 & 0.00 & 2.60 & 2.60 \\
\hline 10 & 0.00 & 0.00 & 0.81 & 0.81 & 0.00 & 0.00 & 1.14 & 1.14 \\
\hline 11 & 0.00 & 0.00 & 0.92 & 0.92 & 0.00 & 0.00 & 1.28 & 1.28 \\
\hline 12 & 0.00 & 0.00 & 0.58 & 0.58 & 0.00 & 0.00 & 0.72 & 0.72 \\
\hline 13 & 0.00 & 0.00 & 0.68 & 0.68 & 0.00 & 0.00 & 0.85 & 0.85 \\
\hline 14 & 0.00 & 0.00 & 0.91 & 0.91 & 0.00 & 0.00 & 0.84 & 0.84 \\
\hline 15 & 0.00 & 0.00 & 1.06 & 1.06 & 0.00 & 0.00 & 0.41 & 0.41 \\
\hline 16 & 0.00 & 0.33 & 1.78 & 2.12 & 0.00 & 0.52 & 2.68 & 3.20 \\
\hline 17 & 0.00 & 0.00 & 3.01 & 3.01 & 0.00 & 0.00 & 3.45 & 3.45 \\
\hline 18 & 0.00 & 0.46 & 5.77 & 6.23 & 0.00 & 0.40 & 5.78 & 6.19 \\
\hline 19 & 0.00 & 0.00 & 4.30 & 4.30 & 0.00 & 0.00 & 6.16 & 6.16 \\
\hline 20 & 0.00 & 0.00 & 1.60 & 1.60 & 0.00 & 0.00 & 3.55 & 3.55 \\
\hline 21 & 0.00 & 0.00 & 0.77 & 0.77 & 0.00 & 0.00 & 1.14 & 1.14 \\
\hline 22 & 0.00 & 1.65 & 3.03 & 4.68 & 0.00 & 2.50 & 3.98 & 6.48 \\
\hline 23 & 0.00 & 0.50 & 1.95 & 2.45 & 0.00 & 0.84 & 3.48 & 4.32 \\
\hline 24 & 0.00 & 0.38 & 2.19 & 2.56 & 0.00 & 0.43 & 1.98 & 2.40 \\
\hline 25 & 0.00 & 0.00 & 5.36 & 5.36 & 0.00 & 0.00 & 9.19 & 9.19 \\
\hline 26 & 0.00 & 0.00 & 1.70 & 1.70 & 0.00 & 0.00 & 2.24 & 2.24 \\
\hline 27 & 0.00 & 0.00 & 3.65 & 3.65 & 0.00 & 0.00 & 5.10 & 5.10 \\
\hline 28 & 0.00 & 0.20 & 2.03 & 2.22 & 0.00 & 0.33 & 3.18 & 3.51 \\
\hline 29 & 0.00 & 0.00 & 1.21 & 1.21 & 0.00 & 0.00 & 1.81 & 1.81 \\
\hline 30 & 0.00 & 0.00 & 1.33 & 1.33 & & * no avai & able data & \\
\hline
\end{tabular}



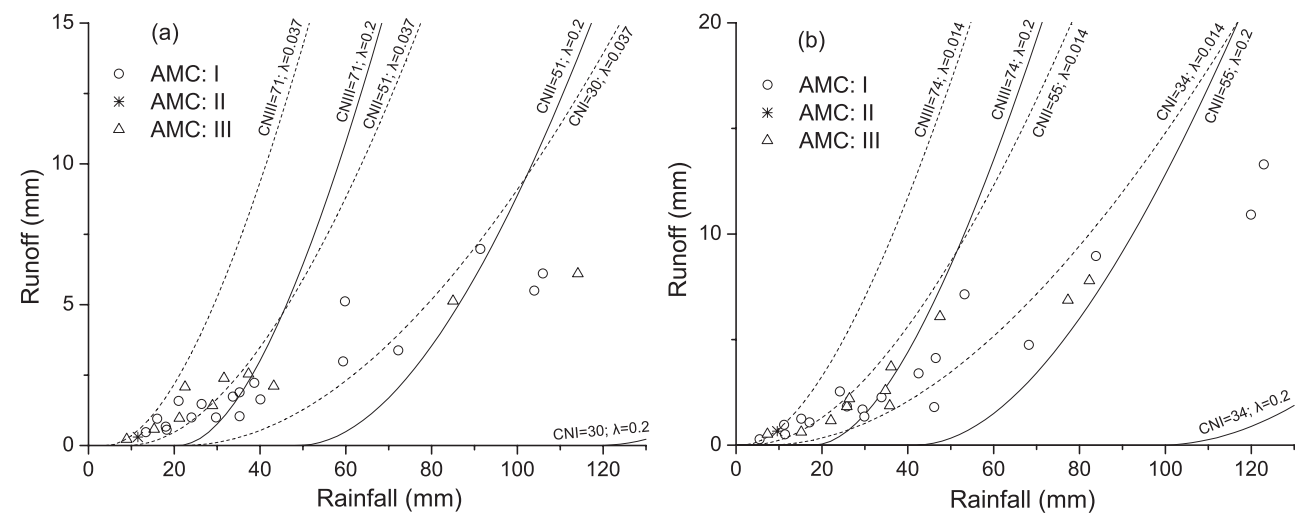

Fig. 3. Measured runoff values in comparison to the runoff predictions of the SCS-CN method. (a) Upper Lykorrema watershed, (b) Entire watershed.
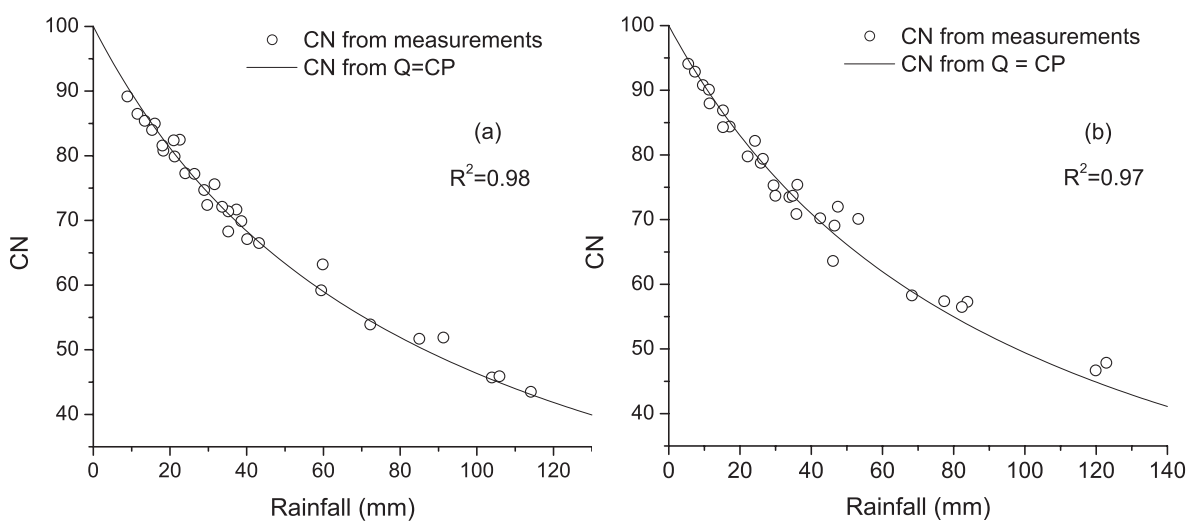

Fig. 4. CN values calculated by Eq. (8) using measured runoff and using runoff estimated by the linear formula Eq. (9), against the total rainfall depth. (a) Upper Lykorrema watershed, (b) Entire watershed.

additional surface runoff, resulting to unexpectedly high total surface runoff values.

\section{Results and discussion}

In a first stage of analysis, the comparisons of the SCS$\mathrm{CN}$ runoff predictions based on the watershed characteristics were only considered. In this stage the watershed is treated as ungauged.

In Fig. 3 the measured runoff values are plotted against the total rainfall for both watersheds. Each data point represents one storm and it is depicted with a different symbol depending on the AMC category. Runoff predictions of the SCS$\mathrm{CN}$ method for the $\mathrm{CN}$ values estimated according to the soil - land cover characteristics of the watershed and the three AMC categories were also plotted. It is obvious, that there is no agreement between the measured and the predicted runoff values for any of the two watersheds.

Baltas et al. (2007), in a previous study that was conducted in the same watershed, tried to determine the initial abstrac- tion ratio, $I_{a}$, of the watershed. According to their results, the average ratio $\left(\lambda=I_{a} / S\right)$ was evaluated to be equal to 0.037 and 0.014 for the Upper Lykorrema watershed and the entire watershed, respectively. The rainfall - runoff $\mathrm{CN}$ - prediction curves, which were calculated using the new suggested initial abstraction ratios, were also plotted in Fig. 3 (dashed lines). It is observed that the use of the estimated $\lambda$ ratio does not essentially improve the obtained predictions. In the same figure, it must also be noted that, contrary to the SCS$\mathrm{CN}$ theory, the AMC III category events are not correlated with higher runoff values. Indeed, in the studied watersheds higher runoff values were observed in dry periods (AMC I). Hawkins (1979) and Steenhuis et al. (1995) also noted in their studies that variation of $\mathrm{CN}$ value, according to AMC category, does not improve the runoff prediction in partial area watersheds.

In a second stage of analysis, the $\mathrm{CN}$ values were calculated for each storm event by Eq. (8) using as input the measured surface runoff amounts. The obtained values of $\mathrm{CN}$ were plotted against the total rainfall depth (Fig. 4). A clear pattern is observed, with $\mathrm{CN}$ declining steadily while rainfall 

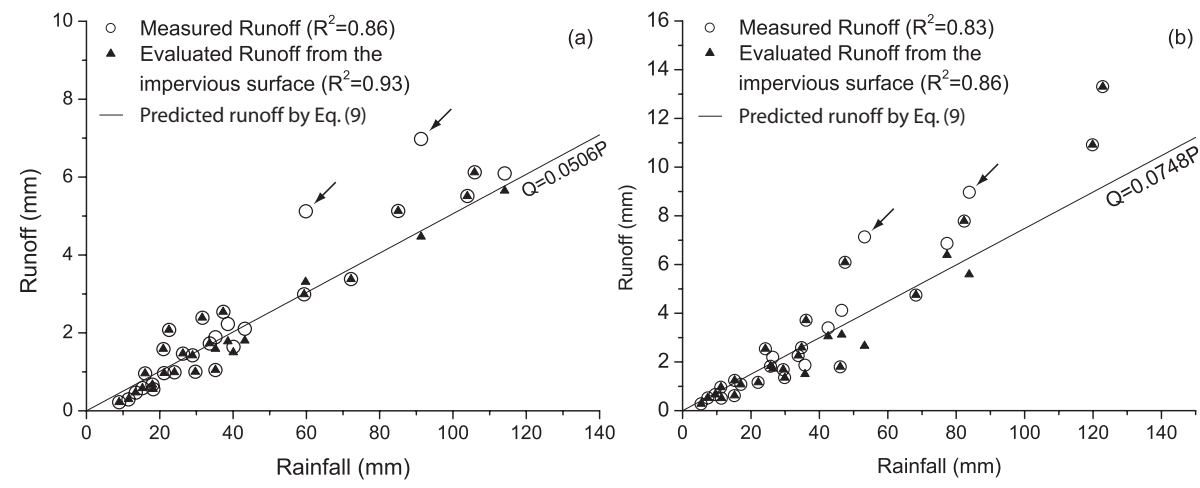

Fig. 5. Measured runoff values, predicted runoff by Eq. (9), and evaluated runoff from the impervious surface, plotted against the total rainfall depth. (a) Upper Lykorrema watershed, (b) Entire watershed.

depth increases. Figure 4 clearly indicates that there is not a unique $\mathrm{CN}$ value that could characterise the watershed behaviour.

For this type of watersheds for which, even for large rainfall depths, the values of $\mathrm{CN}$ decrease steadily without being stabilized at a constant value, Hawkins $(1979,1993)$ suggested that a linear runoff response of the form

$Q=C P$

performed better than the $\mathrm{CN}$ method for predicting surface runoff, where $C$ is the runoff coefficient usually found to be in the range of 0.01 to 0.05 .

Hawkings $(1979,1993)$ made the hypothesis that such behaviour may be attributed to the presence of a constant "impervious" runoff-source-area fraction in the watershed (less than $5 \%$ ) and the value of $C$ in Eq. (10) is close to this fraction value.

The runoff coefficient $C$ in Eq. (10) is assumed to be equal to the fraction of impervious surface of the watershed measured by soil survey (i.e. $C=0.0506$ for the Upper Lykorrema watershed, and $C=0.0748$ for the entire watershed). Then, the $\mathrm{CN}$ values were again calculated by Eq. (8) using as input-runoff the predictions of the linear equation $Q=C P$ (with $C$ identical to the fraction of impervious area) instead of the measured runoff. In Fig. 4 the resulted $\mathrm{CN}$ based on the theoretical $Q=C P$ predictions were compared with the $\mathrm{CN}$ obtained from measured runoff. The comparison indicates a relatively good agreement between the results obtained using measured runoff and predicted by the linear Eq. (10) ( $R^{2}=0.98$ and $R^{2}=0.97$ for the Upper Lykorrema and the entire watershed respectively).

The performance of the linear Eq. (10) is even more elucidated in Fig. 5, in which the measured and predicted runoff values were plotted against the rainfall depths. The straight line represents the runoff predicted by linear Eq. (10), with $C$ assumed equal to the measured impervious fraction.

Figure 5 indicated that although the performance of the linear Eq. (10) is relatively good, however for some spe- cific events (marked in the figure), the linear approach significantly underestimates runoff. Additionally, $C$ values estimated through linear fitting of Eq. (10) to the measured rainfall and runoff values are equal to $0.057\left(R^{2}=0.90\right)$ for the Upper Lykorrema and $0.095\left(R^{2}=0.89\right)$ for the entire watershed and they were found slightly larger than the corresponding measured impervious fractions.

What are the mechanisms producing those significant deviations? The experimental watershed is covered by an impervious surface (of zero hydraulic conductivity), a high hydraulic conductivity coarse textured soil, but also by a medium textured soil of rather moderate hydraulic conductivity. Furthermore, the systematic analysis of rainfall data shows that the two storm-events, for which the deviation of linear prediction is significant, are characterized by particularly high rainfall intensities (maximum 10-min rainfall intensities were equal to $9.4 \mathrm{~cm} \mathrm{~h}^{-1}$ and $4 \mathrm{~cm} \mathrm{~h}^{-1}$ ).

Therefore, the observed deviation may be attributed to the presence of the medium textured area which, for some particularly high rainfall intensities, contributes also to total surface runoff. To elucidate this contribution, the results obtained by the performed numerical simulations were taken into consideration. Indeed, numerical simulation model provided an evaluation of the contributing percentage to the surface total runoff produced from each of the three different soil-type areas of the watershed (see Table 4).

Based on these results, an evaluation of the runoff produced by the impervious surface could be made by decreasing the measured total runoff amount by a percentage, $W_{i}$, calculated from Table 4 as $W_{i}=Q_{\mathrm{Imp}} / Q_{\text {Tot. }}$. Figure 5 presents also the evaluations of runoff produced by the impervious surface obtained using measured data. The evaluated runoff data approach more closely the linear equation with $R^{2}=0.93$ and $R^{2}=0.86$ for the Upper Lykorrema and the entire watershed respectively.

The results support the hypothesis that in watersheds covered with permeable soils the impervious part of the watershed dominates in the direct runoff generation process. 
Furthermore, numerical modeling results provide strong indications of this behaviour. In such watersheds the use of the linear Eq. (10) was proven to be advantageous over the SCS$\mathrm{CN}$ method. In this case the runoff coefficient can be accurately estimated in ungauged watersheds using soil survey and remote sensing techniques. However, caution should be shown, when the linear Eq. (10) is applied for extreme events with very high rainfall intensities. In this case, Eq. (10) may significantly underestimate the produced runoff. This is more clearly shown in Fig. 5 where the performance of the linear formula is very good for all events, except for two specific events where the runoff is significantly underestimated.

The evaluation of the applicability of the SCS-CN method in ungauged watersheds can be proven very important in less developed parts of the world, where hydrologic information is very scarce and SCS-CN method finds a great acceptance for hydrological calculations because of its simplicity.

It is also important to note, that watersheds presenting this behaviour are not very uncommon. Hawkins $(1979,1993)$ studied several watersheds following this behaviour. Additionally, Dingman (2002) stated that many of the natural soils present saturated hydraulic conductivities $K_{S}$ much higher than the normal rainfall intensities. As an example, an analysis of the Soil Geographical Database of Eurasia (2004) indicates that the coarse soils, presenting very high $K_{s}$ values, cover about $37 \%$ of the surveyed area, emphasizing the importance of appropriate choice of the method applied for runoff predictions for watersheds presenting "partial area" behaviour. Based on the runoff generation mechanism investigation, runoff contributing area can be estimated for each storm event. This is very important for water quality and erosion monitoring studies. However, the generalization of these results to other cases requires more tests on a larger set of watersheds, to examine the actual role of impervious zones on a more varied set of conditions.

\section{Conclusions}

The applicability of the SCS-CN method was investigated in a Mediterranean experimental watershed in Greece. The watershed is characterized by the presence of a constant "impervious runoff source area fraction". The remaining area of the watershed is covered by relatively high hydraulic conductivity soils. This analysis concluded, that using the $\mathrm{CN}$ values produced by the standardized procedure (NEH-4 tables), the SCS-CN method overestimates systematically runoff for high rainfall depth events, whereas it underestimates runoff for low rainfall depth events. Furthermore, the analysis indicated that there is a strong correlation between the $\mathrm{CN}$ values and the rainfall depth, with the $\mathrm{CN}$ values decreasing when the rainfall depth increases. The hypothesis that this correlation can be attributed to the existence of an impermeable part in a very permeable watershed was tested in detail, based on a detailed land cover and soil survey using remote sensing and GIS, as well as a numerical soil water flow model. The results support the validity of this hypothesis for most of the events examined, where the linear runoff formula provides better results than the SCS-CN method. The runoff coefficient $C$ of this formula can be taken equal to the percentage of the impervious area. Further analysis of the runoff generation mechanism has shown that for some extreme rainfall intensity storm events, the permeable part of the watershed may partly participate in the runoff production. In this case, the linear formula significantly underestimates the total runoff.

Edited by: R. Merz

\section{References}

Baltas, E. A., Dervos, N. A., and Mimikou, M. A.: Technical note: Determination of the SCS initial abstraction ratio in an experimental watershed in Greece, Hydrol. Earth Syst. Sci., 11(6), 1825-1829, 2007.

Brocca, L., Melone, F., and Moramarco, T.: On the estimation of antecedent wetness conditions in rainfall-runoff modelling, Hydrol. Process., 22(5), 629-642, 2008.

Choi, J., Engel, B. A., and Chung, H. W.: Daily streamflow modelling and assessment based on the curve-number technique, Hydrol. Process., 16(16), 3131-3150, 2002.

Dingman, S. L.: Physical Hydrology Second Edition, Prentice-Hall, Inc., p. 409, 2002.

European Soil Bureau: Soil geographical database of Eurasia at scale 1:1000000 version 4 beta 25/09/2001 \& Pedotransfer Rules 2.0, Dominant surface textural class (infered), JRC, http://eusoils.jrc.ec.europa.eu/ESDB_Archive/ESDBv2/fr_ thema.htm, 2004.

Geetha, K., Mishra, S. K., Eldho, T. I., Rastogi, A. K., and Pandey, R. P.: SCS-CN-based continuous simulation model for hydrologic forecasting, Water Resour. Manage., 22(2), 165-190, 2008.

Hawkins, R. H.: Improved Prediction of Storm Runoff in Mountain Watersheds, J. Irrig. Drain. Div. ASCE, 99(IR4), Proc. Paper 10188, 519-523, 1973.

Hawkins, R. H.: Runoff curve numbers for partial area watersheds, J. Irrig. Drain. Div. ASCE, 105(4), 375-389, 1979.

Hawkins, R. H.: Asymptotic determination of runoff curve numbers from data, J. Irrig. Drain. Eng. ASCE, 119(2), 334-345, 1993.

Hjelmfelt, A. T.: Investigation of curve number procedure, J. Hydraul. Eng. ASCE, 117, 725-737, 1991.

Holman, P., Hollis, J. M., Bramley, M. E., and Thompson, T. R. E.: The contribution of soil structural degradation to catchment flooding: a preliminary investigation of the 2000 floods in England and Wales, Hydrol. Earth Syst. Sci., 7, 755-766, 2003, http://www.hydrol-earth-syst-sci.net/7/755/2003/.

Jain, M. K., Mishra, S. K., Suresh Babu, P., Venugopal, K., and Singh, V. P.: Enhanced runoff curve number model incorporating storm duration and a nonlinear ia-S relation, J. Hydrol. Eng. ASCE, 11(6), 631-635, 2006.

Kannan, N., Santhi, C., Williams, J. R., and Arnold, J. G.: Development of a continuous soil moisture accounting procedure for curve number methodology and its behaviour with different 
evapotranspiration methods, Hydrol. Proc., 22(13), 2114-2121, 2008.

King, K. W. and Balogh, J. C.: Curve numbers for golf course watersheds, Trans. ASAE, 51(3), 987-996, 2008.

Longobardi, A. and Villani, P.: Baseflow index regionalization analysis in a mediterranean area and data scarcity context: Role of the catchment permeability index, J. Hydrol., 355, 63-175, 2008.

Lyon, S. W., Walter, M. T., Gerard-Marchant, P., and Steenhuis, T. S.: Using a topographic index to distribute variable source area runoff predicted with the SCS curve-number equation, Hydrol. Process., 18(15), 2757-2771, 2004.

Michel, C., Andréassian, V., and Perrin, C.: Soil Conservation Service Curve Number method: How to mend a wrong soil moisture accounting procedure? Water Resour. Res., 41, W02011, doi:10.1029/2004WR003191, 2005.

Mishra, S. K. and Singh, V. P.: Another look at SCS-CN method, J. Hydrol. Eng. ASCE, 4(3), 257-264, 1999.

Mishra, S. K. and Singh, V. P.: Long-term hydrological simulation based on the soil conservation service curve number, Hydrol. Proc., 18(7), 1291-1313, 2004.

Mishra, S. K. and Singh, V. P.: A relook at NEH-4 curve number data and antecedent moisture condition criteria, Hydrol. Proc., 20(13), 2755-2768, 2006.

Mishra, S. K., Geetha, K., Rastogi, A. K., and Pandey, R. P.: Longterm hydrologic simulation using storage and source area concepts, Hydrol. Proc., 19(14), 2845-2861, 2005a.

Mishra, S. K., Jain, M. K., Pandey, R. P., and Singh, V. P.: Catchment area-based evaluation of the AMC-dependent SCS-CNbased rainfall-runoff models, Hydrol. Process., 19(14), 27012718, 2005b.

Mishra, S. K., Pandey, R. P., Jain, M. K., and Singh, V. P.: A rain duration and modified AMC-dependent SCS-CN procedure for long duration rainfall-runoff events, Water Resour. Manage., 22(7), 861-876, 2008.

Moretti, G. and Montanari, A.: Inferring the flood frequency distribution for an ungauged basin using a spatially distributed rainfall-runoff model, Hydrol. Earth Syst. Sci., 12, 1141-1152, 2008, http://www.hydrol-earth-syst-sci.net/12/1141/2008/.

Ponce, V. M. and Hawkins, R. H.: Runoff curve number: Has it reached maturity?, J. Hydrol. Eng. ASCE, 1(1), 11-18, 1996.

Rawls, W. J., Shalaby, A., and McCuen, R. H.: Evaluation of methods for determining urban runoff curve numbers, Trans. ASAE, 24, 1562-1566, 1981.

Roger, E. S.: Discussion of "Runoff Curve Numbers form Partial Area Watersheds”, J. Irrig. Drain. Div. ASCE, 106(4), 379, 1980.

Romero, P., Castro, G., Gomez, J. A., and Fereres, E.: Curve number values for olive orchards under different soil management, $S$. Sci. Soc. Am. J., 71(6), 1758-1769, 2007.
Sahu, R. K., Mishra, S. K., Eldho, T. I., and Jain, M. K.: An advanced soil moisture accounting procedure for SCS curve number method, Hydrol. Process., 21(21), 2872-2881, 2007.

Schaap, M. G., Leij, F. J., and van Genuchten, M. T.: Rosetta: a computer program for estimating soil hydraulic parameters with hierarchical pedotransfer functions, J. Hydrol., 251, 163-176, 2001.

Schneider, M. K., Brunner, F., Hollis, J. M. and Stamm, C.: Towards a hydrological classification of European soils: preliminary test of its predictive power for the base flow index using river discharge data, Hydrol. Earth Syst. Sci., 11, 1501-1513, 2007, http://www.hydrol-earth-syst-sci.net/11/1501/2007/.

SCS national engineering handbook, Section 4: Hydrology, Soil Conservation Service, USDA, Washington DC, USA (1956, 1964, 1971, 1985, 1993).

Simanton, J. R., Hawkins, R. H., Mohseni-Saravi, M., and Renard, K. G.: Runoff curve number variation with drainage area, walnut gulch, Arizona, Trans. ASAE, 39(4), 1391-1394, 1996.

Simunek, J., Sejna, M., and van Genuchten, M. T.: The HYDRUS1D software package for simulating the movement of water, heat, and multiple solutes in variably saturated media, version 2.0, US Salinity Laboratory, USDA, ARS, Riverside, CA, USA, 178 pp., 1998.

Singh, P. K., Bhunya, P. K., Mishra, S. K., and Chaube, U. C.: A sediment graph model based on SCS-CN method, J. Hydrol., 349(1-2), 244-255, 2008.

Strahler, R. E.: Hypsometric (area- altitude) analysis of erosional topography, Geol. Soc. Am. Bull., 63, 1117-1142, 1952.

Soulis, K. and Dercas, N.: Development of a GIS-based spatially distributed continuous hydrological model and its first application, Water International, 32(1), 177-192, 2007.

Steenhuis, T. S., Winchell, M., Rossing, J., Zollweg, J. A., and Walter, M. F.: SCS runoff equation revisited for variable-source runoff areas, J. Irrig. Drain. Eng. ASCE, 121(3), 234-238, 1995.

Tyagi, J. V., Mishra, S. K., Singh, R., and Singh, V. P.: SCS-CN based time-distributed sediment yield model, J. Hydrol., 352(34), 388-403, 2008.

van Genuchten, M. T.: A closed form equation for predicting the hydraulic conductivity of unsaturated soils, S. Sci. Soc. Am. J., 44, 892-898, 1980.

Yu, B.: Theoretical justification of SCS-CN method for runoff estimation, J. Irrig.. Drain. Div. ASCE, 124(6), 306-310, 1998.

Zhan, X. and Huang, M.: ArcCN-runoff: An ArcGIS tool for generating curve number and runoff maps, Environ. Model. Software, 19(10), 875-879, 2004. 